\title{
Developing a Conceptual Model for Analyzing and Forecasting Financial Performance of Small and Medium-Sized Businesses
}

\author{
J. Kochieva ${ }^{1}$,E. Sheina ${ }^{2, *}$, A. Payusov ${ }^{2}$, A. Kurdyumov ${ }^{2}$ \\ ${ }^{1}$ South Ossetian State University after A.A. Tibilov, Republic of South Ossetia \\ ${ }^{2}$ Ural State University of Economics, Yekaterinburg, Russia \\ ${ }^{*}$ Corresponding author. Email: shekat@mail.ru
}

\begin{abstract}
Focusing on the trajectory of sustainable economic development requires structuring of the system of financial indicators so as to forecast and evaluate the effectiveness of businesses in the context of global challenges and an unstable internal and external environment. Small and medium-sized enterprises participating in investment projects are the basis for stable business growth and formation of the middle class. However, to forecast the financial results of start-up small and medium-sized businesses is rather difficult due to the lack of financial indicators in the planning period because of the short time of their activity, which requires development and methodological substantiation of the conceptual financial and mathematical model based on an optimization algorithm for assessing the performance of enterprises in the context of their division into start-up and operating small and medium-sized businesses.
\end{abstract}

Keywords: system of financial indicators, investment project, small and medium-sized businesses, conceptual model, financial risks.

\section{INTRODUCTION}

The vector of sustainable development, set by the postulates of the UN General Assembly [1], which caused changes in the state policy priorities in most countries of the world in the context of globalization with a pronounced social orientation, and formed the concept of sustainable development, predestinating the relationship of the current generation evolution with the interests of future generations, predetermined the importance of stimulating and implementing investment projects of small enterprises, namely startups that grow in a stable state of the national economy into small and medium-sized businesses [2-4].

When small and medium-sized businesses participate in investment projects, one of the key factors is the profitability planned to be received in the future, which can be calculated in various ways $[5 ; 6]$.

The calculation of the amount of funds that the investor plans to receive at the moment of selling his share in the project is usually done according to the following formula:

$$
D=I(1+q)^{t}
$$

Where: D is the amount of income that the investor plans to receive, thousand rubles; $I$ is the amount of investments, USD; $\mathrm{q}$ is the rate of return, \%; $\mathrm{t}$ is the time period of the investor's stay in the project (planned by the investor), years.

The value of the enterprise at the time of the investor's exit from the project can be calculated according to the following basic formula:

$$
S_{i}=M \cdot P_{t}
$$

where: $\mathrm{Si}$ is the cost of the enterprise at the time of exit, thousand rubles; $M$ is the value of the numerical multiplier; Pt is net profit for the year, thousand rubles.

These methods for assessing investments have confirmed their effectiveness in calculating the financial indicators of operating small and medium-sized businesses. However, in relation to the activities of startups (start-up businesses with a period of activity up to 1 year), the practical application of these indicators for specific ideas / products may have a lot of options [7 $-9]$. 
The possibility of obtaining and using investments by startups depends on the fulfillment of two main tasks: identifying the favorable conditions that are formed under the influence of state financial regulatory policy levers and the results of their activities, as well as identifying the level of risks permissible to attract investors.

The high risks and uncertainty contribute to the extremely high attention of investors to the startups' evaluation. The problem of asymmetric information, for the development of which the American scholars George Arkelof, Michael Spence and Joseph Stiglitz were awarded the Nobel Prize in 2001, remains practically not covered in the scientific literature [1012]. This justifies additional attention to the formation of a conceptual financial and mathematical model for assessing startups' profitability so as to make a decision upon their financing by both financial institutions and private investors.

There are various approaches to assessing startups' performance, but no formalized model has yet been recognized, which would satisfy the requirements of all counterparties for such projects' implementation.

\section{MATERIALS AND METHODS}

The research methodological framework is based on the provisions of investment theory, finance theory and management theory, as well as a problem-oriented approach, which takes into account the complexity of finding sources of financing at all life cycle stages of small and medium-sized businesses of all industries and forms of ownership, especially in the context of global challenges and the necessity of financial risks minimization.

In the process of research, the authors used methods of dialectical, cause-and-effect, and structural-logical analysis, which enabled to systematize the theoretical aspects of assessing the return on investment in startups and to expand approaches to predicting the financial performance of start-up small and medium-sized businesses.

Also, in the course of study, the authors used the expert assessments method, which enabled to determine gradations of possible financial risks arising from investing in business projects, which are reflected on the scale of boundaries of general risk zones.

\section{RESULTS AND DISCUSSION}

High-risk investment projects, which include projects implemented by startups, are traditionally characterized by the formation of a system of financial and economic efficiency and risk minimization indicators.
When assessing the risks and, therefore, the possible effectiveness of financing these investment projects, especially those implemented by startups, it is not the unreal data or the formation of predicted values that are important to monitor, but the assessment which is based on expert opinion and can be characterized as a "level of conviction" [2].

Based on the goals and needs of investment projects financing, the authors developed a financial and mathematical model based on an optimization algorithm for assessing the performance of startups implementing these projects, which would satisfy the requirements of both an investor (financial institutions, private investors) and an entrepreneur (borrower of financial resources). The model is also to be consistent with the accepted assessment practice.

The model is based on the following statements:

1) general assessment of economic efficiency (Ee) is carried out according to the formula (3);

2) relative assessment of the project (R) can be calculated by the formula (4);

3) based on the abovementioned scientific statements, and when calculating the risk coefficient $(\mathrm{Kz})$, we consider it necessary to take into account the degree of risk, which depends on the market development stage and the startup life cycle stage and which is inherent in the investment project (including the risks, that characterize this product / service group):

$$
K_{z}=\prod K=K_{r} \cdot K_{p} \cdot K_{t}
$$

where: $\mathrm{Kz}$ is the risk coefficient characterizing the overall risk of an investment project; $\mathrm{Kr}$ is the risk coefficient characterizing the risk of possible project failure; $\mathrm{Kp}$ is the risk coefficient characterizing the degree of liquidity risk; $\mathrm{Kt}$ is the risk coefficient characterizing the degree of risk inherent in a given group of goods / services.

Given that financial and economic efficiency is a relative (qualitative) indicator, the risk coefficient is an absolute (quantitative) indicator, and that when taking them into account it is necessary to choose the same dimension, it is more expedient to use relative values for their comparison (after all, various investment projects differ significantly in quantitative indicators). In this connection, we propose the following formula for calculating risks:

$$
P=\frac{1}{1-K_{z}}=\frac{1}{1-K_{r} \cdot K_{p} \cdot K_{t}}
$$

These proposals for risk calculating are based on the approach of the mathematical method of distances (or the difference between the actual and maximum values) and take into account the selected scale for assessing the 
risk coefficient (from 0 - a situation when there is no risk, to 1 - a situation when the risk is maximum possible). When applied to an individual assessment of risks, this approach takes into account not their actual values, but their ratings (distances to the maximum value).

Based on the above, we propose the following financial and mathematical model for evaluating a startup's effectiveness:

$$
R=\frac{E_{n}}{B_{n}} / \frac{1}{1-K_{z}}=\frac{\sum_{i=1}^{n}\left(D_{i} \cdot(1+q)^{-i}-B_{i} \cdot(1+q)^{-i}\right)}{\sum_{i=1}^{n} B_{i} \cdot(1+q)^{-i}} / \frac{1}{1-K_{r} \cdot K_{p} \cdot K_{t}} \rightarrow \max
$$

where: $\mathrm{R}$ is the "efficiency-risk" indicator; $\mathrm{E}_{\mathrm{n}}$ is the effect from implementation of the considered investment project, thousand rubles; $\mathrm{B}_{\mathrm{n}}$ is the expenses for the investment project implementation, thousand rubles; $\mathrm{i}$ is the period serial number; $\mathrm{Bi}$ is the project costs in the 1st period, thousand rubles; Di is the income from the investment project implementation in the i-th period, thousand rubles; $\mathrm{n}$ is the number of project implementation periods, years; $\mathrm{q}$ is the discount rate; $\mathrm{K}_{\mathrm{z}}$ is the overall risk of the investment project; $K_{r}$ is the risk coefficient characterizing the risk of possible project failure; $K_{\mathrm{P}}$ is the risk coefficient characterizing the degree of liquidity risk; $K_{t}$ is the risk coefficient characterizing the degree of risk inherent in a given group of goods / services.

The model proposed by the authors is based on the statement that the "efficiency-risk" indicator takes into account how effectively the investor funds are invested in the project implementation per unit of risk and enables to carry out a comparative analysis of startups in order to select the most acceptable of them. This indicator is similar to the variation coefficient, which is used in risk management and which shows the risk (the degree of deviation of the obtained values) per unit of the result (profit, profitability).

In the financial and mathematical model developed by the authors (Formula 5), it is proposed to simultaneously combine two conflicting objective functions (the first is to be maximized, while the second is to be minimized), therefore the model indicators are to have the following restrictions (Formula 6):

$$
\begin{aligned}
& f_{1}=E / B \rightarrow \max \\
& f_{2}=1 / 1-K_{r} \cdot K_{p} \cdot K_{t} \rightarrow \min \\
& \left\{\begin{array}{l}
E_{\max }>E>0 \\
E \geq B>0 \\
K_{r} \neq 0 \\
K_{p} \neq 0 \\
K_{t} \neq 0 \\
\vec{K} \in R
\end{array}\right.
\end{aligned}
$$

High-risk investment projects implemented by startups, which are characterized by $100 \%$ of at least one of the risk types, that is $\mathrm{K}=1$, are not accepted for consideration, because any of the individual risk types (the risk of possible project failure, liquidity risk or risk inherent in this group of goods / services) can lead to bankruptcy of the startup.

The authors' model is universal in nature, and yet, given the peculiarities of the financial and economic activities of start-up and operating small and mediumsized businesses, as well as the differences in their participation in investment processes, we propose to introduce restrictions in the calculations, which, in the first place, relate to investment risks.

The model developed by the authors is of particular importance and relevance for high-risk investment projects, which among others include innovative and socially oriented projects [13-16].

The emergence of innovative ideas and technological solutions, the development of startups is increasingly associated with the specificity of social entrepreneurship. The latter is classified as a certain type of business process or business model, with the enterprise itself, the economic entity and the laws of its activities and financing being excluded from direct consideration. It is the development of social entrepreneurship that ensures investment projects in the country's economy in such important sectors as ecology, domestic tourism, culture, art, which undoubtedly requires a sufficient theoretical and methodological basis for scientific research in this field [17].

The projects under consideration are based on a new, innovative business idea aimed at meeting new social needs while obtaining a fundamentally new level of socio-economic effect, which, on the one hand, is potentially attractive for investors in case of successful implementation and replication of the project, but on the other hand, is associated with increased risks due to the uncertainty of final outcomes.

So, for socially oriented startups, we propose to generalize the following restrictions of target functions 
to a model for assessing their activities, given the risks corresponding to the boundaries of the minimum risk zone (Formula 7).

For each participant in the investment process, the problem of financial stability is important, therefore, the restrictions of target functions should include the possibility of capital loss and the permissible limits of such losses. We choose net profit, gross income and equity as the main indicators of a startup's financial condition and propose the following restrictions on target functions in the model for assessing a startup's performance, subject to minimal risks and given the possibility of capital losses (Formula 8).

$$
\begin{aligned}
& \left\{\begin{array}{l}
E_{\max }>E_{n}>0 \\
E_{n} \geq B_{n}>0 \\
0<K_{r} \leq 0,25 \\
0<K_{p} \leq 0,25 \\
0<K_{t} \leq 0,25 \\
\vec{K} \in R \\
0<K_{z} \leq 0,015
\end{array}\right. \\
& \left\{\begin{array}{l}
E_{\max }>E_{n}>0 \\
E_{n} \geq B_{n}>0 \\
B_{n} \leq D_{\text {ear }} \\
0<K_{r} \leq 0,25 \\
0<K_{p} \leq 0,25 \\
0<K_{t} \leq 0,25 \\
\vec{K} \in R \\
0<K_{z} \leq 0,015
\end{array}\right.
\end{aligned}
$$

where $\mathrm{D}_{\text {вал }}$ is gross income.

For medium-sized enterprises, these restrictions can be less stringent and reach the boundaries of the highrisk zone (Formulas 9 and 10).

$$
\left\{\begin{array}{l}
E_{\max }>E_{n}>0 \\
E_{n} \geq B_{n}>0 \\
0<K_{r} \leq 0,5 \\
0<K_{p} \leq 0,5 \\
0<K_{t} \leq 0,5 \\
\vec{K} \in R \\
0<K_{z} \leq 0,125
\end{array}\right.
$$

$$
\left\{\begin{array}{l}
E_{\max }>E_{n}>0 \\
E_{n} \geq B_{n}>0 \\
B_{n} \leq \Pi_{\text {чист }} \\
0<K_{r} \leq 0,25 \\
0<K_{p} \leq 0,25 \\
0<K_{t} \leq 0,25 \\
\vec{K} \in R \\
0<K_{z} \leq 0,015
\end{array}\right.
$$

where $\Pi_{\text {чист }}$ is the net profit.

Thus, various types of restrictions determine the permissible limits of risks and costs for businesses of various size, which will ensure financial stability of their functioning and development in the market.

Other restrictions can be introduced to the proposed model. For instance, the time factor can be taken into account (in that case, $\mathrm{n}$ - the number of periods - will have a certain maximum value).

Based on the results of the developed model, the actual limits of risk levels for different types of businesses were determined $(\mathrm{Kz} \leq 0.015$ - for small businesses, $\mathrm{Kz} \leq 0.125$ - for medium-sized ones, $\mathrm{Kz} \leq$ 0.421 - for large ones).

Thus, the scale of the general risk zones boundaries in investment projects will vary for enterprises of different size and scale of activity.

\section{CONCLUSIONS}

The proposed restrictions (Formulas 6-10) to the model (Formula 5) are based on the authors' hypothesis, have a generalized character and can be further applied in practical research in order to identify characteristic features and more accurate values for startups of different types of activity, as well as operating small and medium-sized businesses. However, in the current situation (the formation of socially oriented investment, the absence of an open accessible information base), this seems rather unlikely.

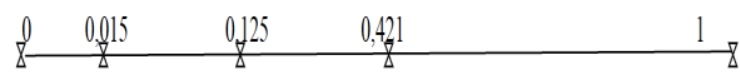

Figure 1 Scale of general risk zones boundaries in investment projects implemented by small and mediumsized businesses [compiled by the authors]

The use of the authors' conceptual financial and mathematical model for analyzing and forecasting of the financial performance of small and medium-sized businesses, including startups, will enable institutional and private investors to better select investment projects 
for financing, as well as to minimize their own financial risks.

\section{ACKNOWLEDGMENTS}

The reported study was funded by RFBR and MES RSO, project number 21-510-07003"Formation of a financial and investment mechanism for supporting small businesses in the conditions of the formation of a young state."

\section{REFERENCES}

[1] United Nations, Resolution adopted by the General Assembly on 6 July 2017, Work of the Statistical Commission pertaining to the 2030 Agenda for Sustainable Development, 2017. https://www.un.org/en/development/desa/populatio n/migration/generalassembly/docs/globalcompact/ A_RES_71_313.pdf.

[2] Ye.G. Sheina, Financing the investment process in the context of the development of socially oriented investment based on the risk-evolutionary approach, Yekaterinburg: AMB Publishing House, p. 312 .

[3] YA. P. Silin, Small and medium business of the Sverdlovsk region: state, potential and development prospects, Yekaterinburg: USUE Publishing House, 2013, p. 215.

[4] V.P. Ivanitskiy, V.A. Tat'yannikov, Information asymmetry in financial markets: challenges and threats. In: Economy of the region, 14(4) (2018) pp. 1156-1167. DOI: https://doi.org/ $10.17059 / 2018-4-8$.

[5] Z.L. Dzakoyev, V.V. Dzhabiyev, ZH.G. Kochiyeva, Assessment of the regulatory impact of the implementation of investment projects in the Republic of South Ossetia. In: Bulletin of the North Ossetian State University. K.L. Khetagurov, 1 (2013) pp. 218-222.

[6] A.A. Konyayev, Analysis of socio-economic indicators of Russia in conditions of ineffective management of financial flows of the banking sector. In: Banking, 11 (2020) pp. 46-50.

[7] Ha. Joohyung, Conditional conservatism and labor investment efficiency, 2018. DOI: https://doi.org/10.1016/j.jcae.2018.05.002.

[8] Kostopulos Dimitrios. Disentangling investor sentiment: Mood and household attitudes towards the economy, 2018. DOI: https://doi.org/10.1016/j.jebo.2018.08.003.

[9] N. Sekerci, Factors Associated with Strategic Corporate Decisions in Family Firms: Evidence from Sweden. In: International Review of Finance, pp. 45-75 (2020). DOI: https://doi.org/ 10.1111/irfi.12217.

[10] J. Kaczmarek, The Mechanisms of Creating Value vs. Financial Security of Going Concern Sustainable Management. In: Sustainability, 11(8) (2019) pp. 1-24. DOI: https://doi.org/ $10.3390 /$ su11082278.

[11] Y. Kim, D.S.T. Matkin, Financial Conditions and Internal Control Deficiencies: Evidence From New York Counties. Public Budgeting \& Finance, pp. 45-69 (2020). DOI: https://doi.org/ $10.1111 /$ pbaf.12246.

[12] J. Oradi, K. Asiaei, Z. Rezaee, CEO Financial background and internal control weaknesses. In: Corp Govern Int Rev, 28 (2020) pp. 119-140. DOI: https://doi.org/ 10.1111/corg.12305.

[13] D. Celebi, I. Pirnar, E.D. Eris, Bibliometric analysis of social entrepreneurship in gastronomy tourism. In: Tourism, 68(1) (2020) pp. 58-67.

[14] Vijaya Sherry Chand, A Research Agenda for Social Entrepreneurship. In: Journal of entrepreneurship, 29(1) (2020) pp. 206-211.

[15] Nicolae Cuta, Social Entrepreneurship. An Affirmative Critique. In: Voluntas, 30(3) (2019) pp. 614-615.

[16] Marcelo Dionisio, The evolution of social entrepreneurship research: a bibliometric analysis. In: Social enterprise journal, 15(1) (2019) pp. 2245.

[17] E.G. Shein, A.A. Payusov, A.V. Kurdyumov, Formation of socially oriented projects using the financial and investment mechanism in the field of environmental management. In: E35 Web of Conferences. Cep. «International Scientific and Practical Conference «Development of the AgroIndustrial Complex in the Context of Robotization and Digitalization of Production in Russia and Abroad», DAIC 2020» p. 6035 (2020). 